\title{
Playing on the Boundaries: A Childhood across Cultural and Geographical Lines
}

\section{RANIA HAFEZ}

Department of Education and Community Studies, University of Greenwich, UK

This is not a conventional paper. It is a personal narrative. It is subjective not only to its author but to the child-self of the author. It is not a detached academic look at a personal history. In fact it could be described more as 'archaeological' than historical; an examination of what appears to be a random collection of fragments of a personal history, found in memory and artefacts of a childhood. The telling of the story is an attempt to understand the development and trajectory of an individual identity across geographical, cultural, and religious boundaries. It is not the whole story, but it gives the writer and the reader a few selected pieces of the full picture.

KEYWORDS childhood, play, culture, memory, narrative

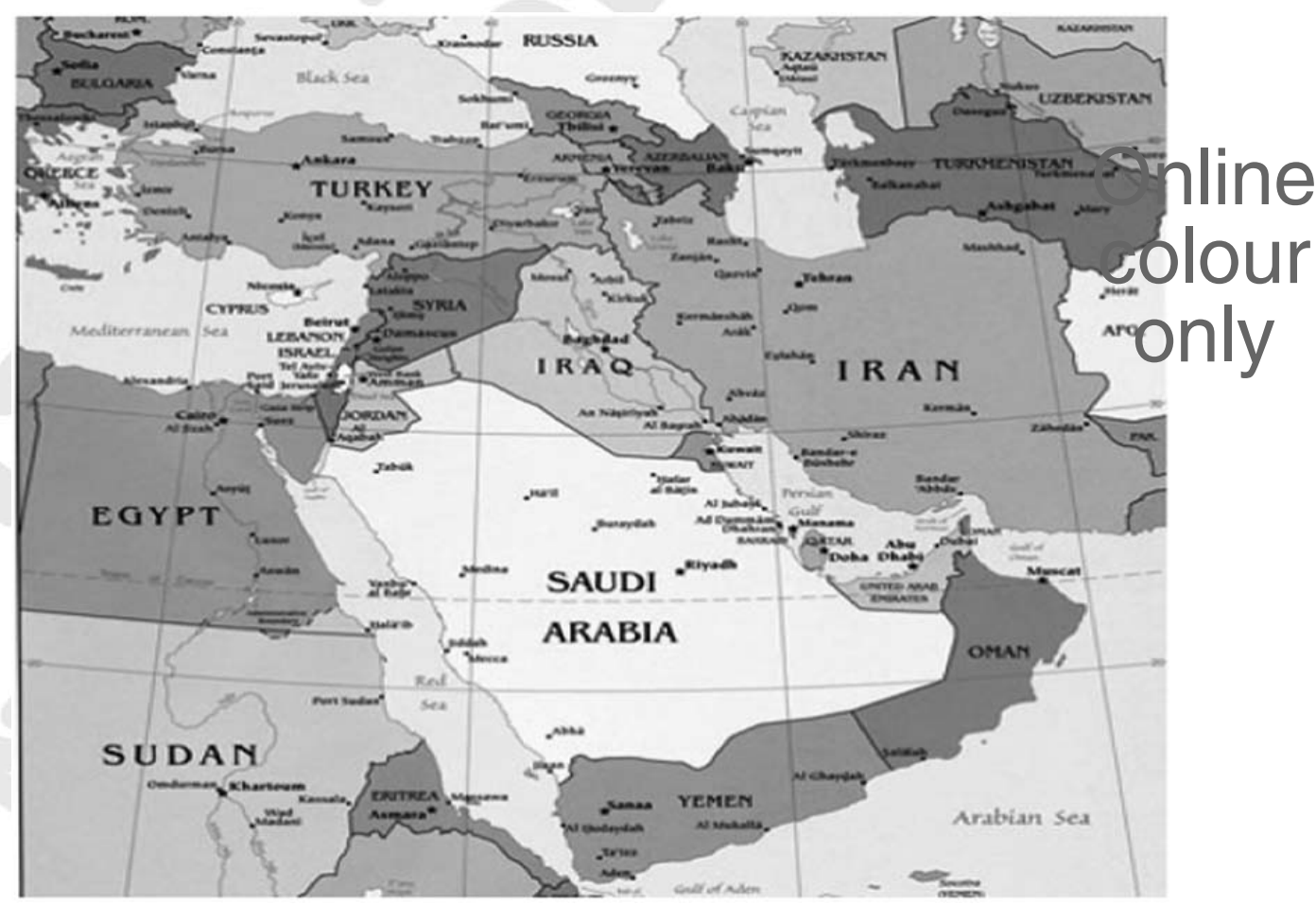




\section{Introduction: Confounding Expectations}

In crossing a border (...or two) the foreigner has changed his discomforts into a base of resistance, a citadel of life. (Kristeva, I99I: 8)

Perhaps the most poignant and abiding memory I have from my early childhood is being waved goodbye by my smiling mother as women in long black robes and veils dragged me away crying. As dramatic as this image sounds, it was actually my first day at boarding school. I was four years old, and the women in black were benign Catholic nuns. Readers may wonder about the significance of recounting this memory. If you had a picture of the author now you would see a middle-aged woman in a Muslim hijab (head cover), so the fact that as a child I spent my formative years boarding in a Catholic convent school gives some indication as to the unconventional nature of my childhood.

When people in the West think of childhood in a multicultural context my experience has been that their expectations are always of something 'traditional'; colourfully quaint and faintly exotic. Since arriving in the UK thirty-two years ago, I have often engaged in conversations, both personal and professional, about my Middle Eastern childhood. What I recount always seems to confound my interlocutors' expectations. Most people have very little idea what the Middle East was like in the sixties, although some may have heard of Lebanon's capital Beirut being referred to as the 'Paris of the East'. A flattering concept, but a highly exaggerated one. There was much about Beirut that belied its glitzy exterior. The undercurrents that led to the devastating eighteen year civil war in Lebanon were already manifesting in my early childhood (Makdisi, I996).

In this article I will be using personal testimony to demonstrate the complex and surprising nature of a Middle Eastern childhood in the I960s. I will focus on my childhood in the first five years leading to that October afternoon when I was handed over to the nuns in the French convent school. In particular I will be looking at key artefacts: the toys I played with, early photos and the commentary scribbled on their backs, and my own recollection of anecdotes and events, as well as conversations with my parents about their memories of these early days.

Construction of history through personal testimony is fraught with complexity and contradiction. Bignold (201I: I9) suggests that it may even be labelled 'ethnographic fiction'. A personal narrative is particular to one person and cannot by itself give a rounded perspective. Recollection is not only subject to the veracity and accuracy of memory but also open to interpretation according to the present condition and state of mind of the narrator. Thus 'objective' and 'accurate' are not claims I make for this paper. As long as the narrator is aware and reminds the reader of the subjective construction of a social reality, then the work has validity and credibility:

What is key to creative non-fiction is its validity and credibility, given that it is based on real events, allowing the voices of those whose stories are being told to be heard with authenticity and validity. Alongside this, the creative nature of it enables the (writer) to construct a story which will draw the reader in and help him/her to 
understand something of the lived experiences underpinning the narrative. (Bignold, 2OII: 27)

Hence, through weaving this personal narrative, I hope to outline some of the wider patterns that were at play in the life of a post post-colonial child, at a time of great social, economic, and political change in the region, though these would only be patterns discerned from recollected memories and chosen artefacts. And no doubt the very act of selecting these memories and artefacts in preference to others betrays the character and priorities of my current self as opposed to what the child experienced.

Perhaps the most difficult challenge in writing this paper has been pinning the memories and interpretations to a suitable theoretical framework. This was partly because I did not want the theory to distract from the story and also because the child me would not have made sense of what she was experiencing with reference to theory. So this is an indulgent paper. Short on theory and somehow disjointed, but then that is the nature of memory. In looking back in the way I do in this paper, I hope to give you and myself a picture, albeit fragmented and incomplete, of a childhood that presaged a life lived on boundaries.

\section{Setting the Scene: My Parents}

As this is about my childhood, my starting point has to be my parents.

A very handsome couple and very 'modern' in their outlook, as fading photos from their youth attest. Many 'Western' friends have been surprised by these images of my parents. My mother's clothes are very European and 'daring', especially in the present context of conservative Islamic attire, including my own. Yet the clothes were only an outward manifestation of an outlook that looked to emulate Europe and the West in the quest for progress and modernity, especially by the elite families such as the one to which my mother belonged (Barakat, I993; Makdisi, I996).

My parents had met and married in Beirut in 1962 and a year later I was born. Lebanon at the time was in the second decade after independence (gained 22 November 1943). It was a multi-faith and multi-confessional society, later to become sharply divided over sectarian lines, but then still basking in the postindependence glow. The capital Beirut and its middle class inhabitants prided themselves on being considered the 'Paris of the East'. The relationship between the Lebanese elite and the French colonialists had been an amicable one (Makdisi, I996). Lebanon was a French protectorate for just two decades, the Christian French being seen as the 'liberators' of the majority Christian country from the rule of the Muslim ottomans (Makdisi, 1996).

The sectarian make-up of Lebanon holds the roots for both its progressive modernist tendencies and its political divisions and civil strife. Lebanon was at the time unique in the Middle East for having a Christian majority although neighbouring countries, notably Palestine, also had a significant Christian community. And not that the modernists' tendencies were confined to the Christian community, but notable figures in literature, music, and cinema had come from the various small religious sects of the region. It seems that the diversity 


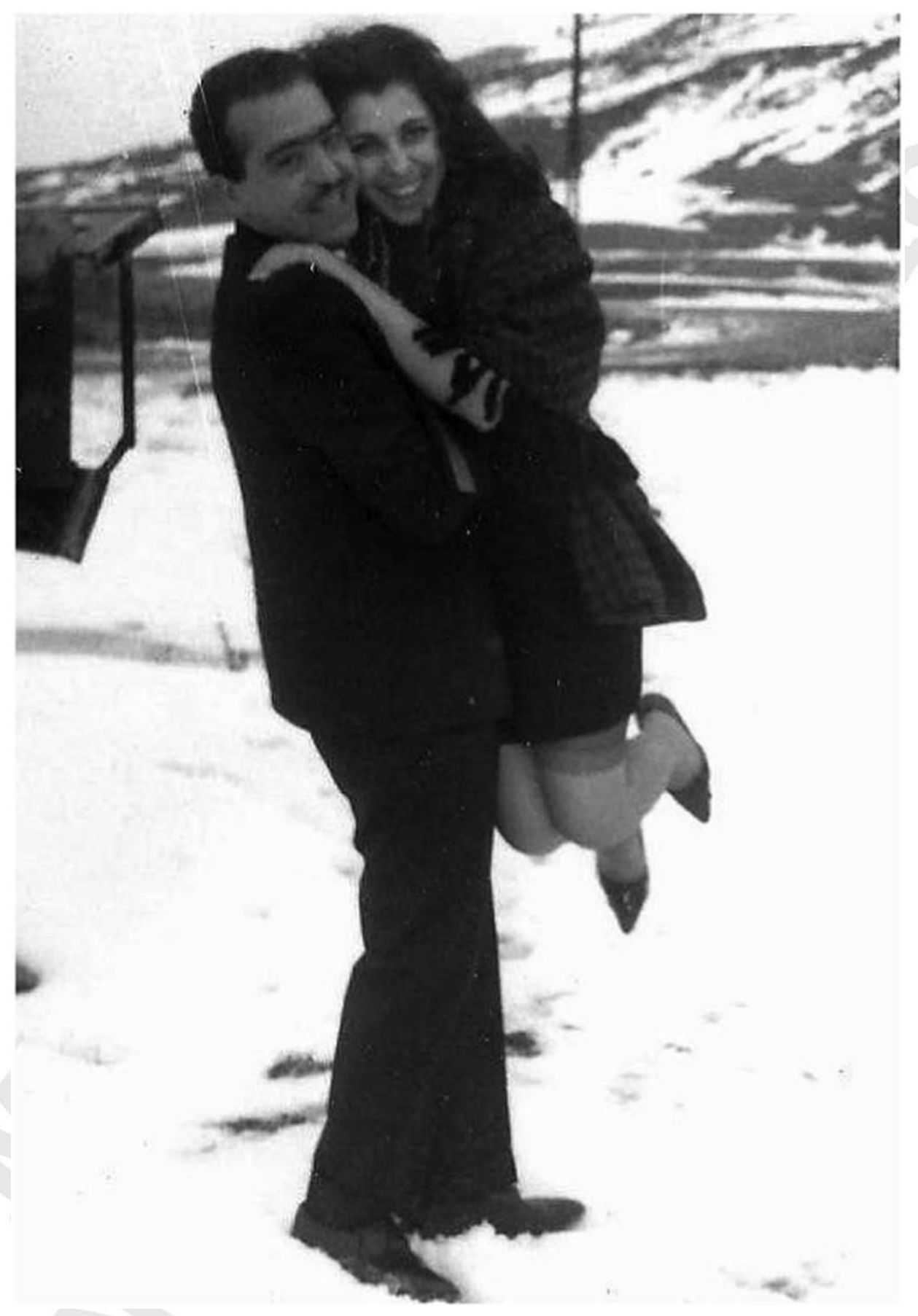




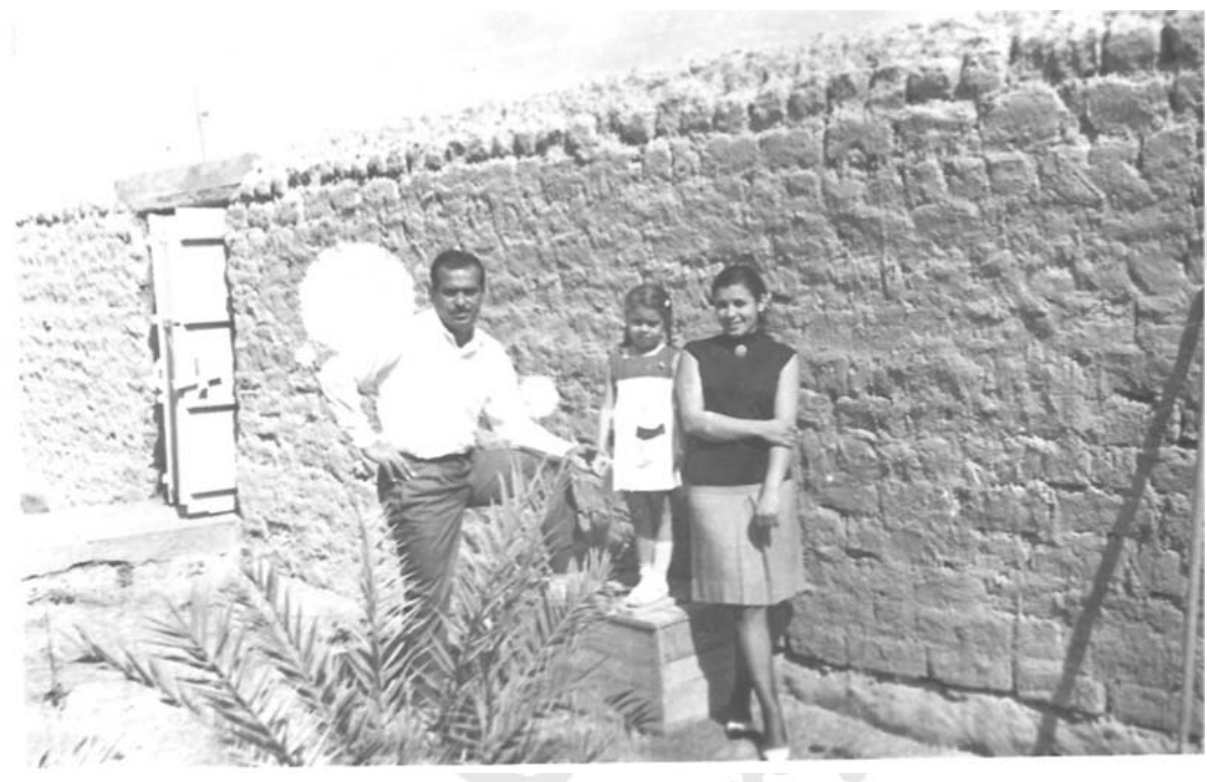

FIGURE 2 In our traditional Emirati house in Al-Ain, Abu Dhgabi.

of the population and its desire of its elite to develop a modernist identity acted as a catalyst to foment and accelerate social and cultural development (Watenpaugh, 2006).

In this Lebanon, in this Beirut, my parents met and married. Their photos show a couple who looked and behaved like movie stars. Like countless Lebanese before them their horizons stretched beyond the Mediterranean sea. Within a few months of their marriage my father decided that there were new exciting opportunities beckoning in the oil rich Arabian Gulf states and flew out there with my mother and myself following soon after. I was one. My parents had planned to be in the Gulf only for a few years while my father made our fortune, but it was to be two decades before they finally left to go back home to Lebanon.

\section{Crossing the First Boundary: Emigration}

Landing in Dubai, it was a very alien world that greeted my mother and me. From a lush balmy modern Lebanon my mother and I stepped into a hot dusty undeveloped Dubai. The seven emirates that eventually formed the United Arab Emirates on 2 December 197I (six became the UAE on that date with the seventh Ras-Al-Khaimah joining a year later), were then small semi-autonomous desert outposts (http://www.zu.ac.ae/main/en/_careers/living/story.aspx). The locals were mostly traditional Bedouins interspersed with a few trading families of Iranian and Indian origins who had settled around port areas such as Dubai over the nineteenth and twentieth centuries (Gettleman and Schaar, 2003; Thesiger, I959).

Dubai, a little autonomous emirate, was a relatively new town that had sprung up around a small port in the south eastern side of the Arabian Peninsula on the shores of the Persian Gulf. Out of it, trading sea routes had flourished. To this day 
Dubai owes its success to its flair for trading rather than oil, of which it has very little. My parents were expatriates, hoping to make their life and fortune in the newly wealthy but as yet undeveloped region.

Although my parents and the locals shared the 'Arab' ethnicity as we recognise it today, then they saw themselves as ethnically very different. The Arabs of the Levant considered themselves far more cultured than, and dare I say even superior to, the oil-rich but traditional Bedouins. Levantine Arabs had embraced European style modernity in their clothing, social habits, and political structures, including democratic practices such as the universal franchise. Lebanon in particular was a leading centre for literature, music, and art. It had several universities and a wellestablished public school system. In contrast, the emirates were just emerging into modernity. Expatriates like my parents were enticed there as the country embarked on nation building; primarily its infra-structure and economy. Social development lagged slightly behind in terms of education, health, and other social indicators.

For my parents, their belonging and allegiance were to Lebanon. Their Lebanese identity was in sharp relief and contrast to the local Arab/Bedouin identity. There was no question of integration. Neither the hosts nor the new arrivals expected or countenanced it. Years later I would be chided by my mother for speaking colloquial Arabic in a non-Lebanese accent, although the first language she taught me was French! (Pollock and Van Reken, 2009).

So here I was being brought up by my ultra-modern stylish Lebanese mother, in a desert country where women still wore traditional burqas and were segregated from men. I have often spoken to her about her experiences in the Emirates. Her first impressions were of searing heat, dust, local people exotically attired with heavy accents she couldn't understand, and lots of creepy crawlies that invaded our apartment: in short, daily conditions far removed from the urban temperate comfort of Beirut.

From the outset though, my mother in particular was adamant that she would maintain and even reinforce what she saw as her superiority to the locals. We mostly socialised with fellow expatriates from Lebanon, and although she came to befriend a few local women, including the sister of the ruler of what was to become the United Arab Emirates, she never adopted their social or cultural habits. In fact, to do so would have probably been considered disrespectful. My mother asserted her European-like Lebanese traits. These traits were looked on with bemusement and perhaps even admiration by local women, though the latter seemed equally proud of theirs. One anecdote I remember clearly is visiting Sheikha Salama, the ruler's daughter in her old palace in Al-Ain. I was around four years old. I remember the small door in the large wooden gate that would be opened for my mother and I to go through; then walking through what seemed to little me to be a forest of palm trees and eventually coming to a traditional fort-like dwelling, a dusty golden colour of sand. It was a strictly female household with men confined to guarding the perimeter. Once in, we would be met by one of the female attendants and ushered to Sheikha Salama's presence. She would be sitting with her female attendants, all of them including her wearing the traditional burqa. She never took it off in public although she was invariably in an all women assembly. I remember asking her to take her burqa off so I could see her face. Her response 
produced much laughter by all assembled though I did not understand it at the time. Years later my mother would tell me that how Sheikha Salama had responded to my asking her to remove her burqa: 'If your mother takes off her knickers, I'll take off my burqa.' Great sense of humour, but more importantly a clear indication that although the friends were from different cultural traditions, they respected the differences and were quite capable of equating their respective importance. Hence, from an early age I learnt about boundaries of difference and measures for equating that difference (Pollock and Van Reken, 2009).

Despite living in Dubai, my mother and I often went back Lebanon to visit my grandparents and the extended family. That meant that I grew up learning how to go back and forth across geographic and cultural boundaries, able to make subtle adjustments of behaviour to suit the two different societies.

\section{Crossing the Second Boundary: The Changing Role of Women}

The next exhibit in this narrative is a small photograph of me as a toddler with my father at one of his building sites in Dubai. Like other expatriates my father was an entrepreneur and had started his own construction company. My mother, an upper middle-class modern Lebanese woman, was a housewife.

There are two interesting features about this photo. The first one is the fact that I am with my dad at his workplace. In a society (the Emirates) where women were still very much segregated from men and expected to follow traditional roles, it is not usual to have a little girl go to her father's workplace let alone be photographed holding a trowel. Yes, I was only a toddler, and this could be seen as a joke, but it does show a new place for children, especially female ones. With relative affluence comes a new position for children in the family, reflecting the changing role of childhood in other societies as they developed. This could also be a reflection on my father's status. Being the boss he could take a child with him to work. In fact, in subsequent years my younger brother and I would often accompany my father to his office or one of his building sites, and on recollection we would be the only children there and were also very well looked after by my father's employees, who no doubt were at times irritated by having us running freely around the place.

The second distinctive feature about this photograph is my mother's comment scribbled on the back. It says in Arabic: 'Rania giving her father engineering instructions'. The photograph was probably sent to the family back in Lebanon to show them some of our life in the emirates. In both features this photograph exemplifies the social changes already taking place. My mother, the housewife, was writing about her daughter, the engineer. The comment may have been light-hearted, after all I was barely two years old, but it was an indication of the generational differences already manifesting themselves as parental aspirations. My mother, being a woman, was discouraged by her older brother from going to university (her brother had insisted that 'good' girls do not go to university). Although she complied, she knew that the social changes taking place meant that she could aspire for her own daughter to experience the academic and professional achievements that were denied her.

But what is even more surprising is that my mother is visualising a future for her daughter far removed from the reality for many women in the Gulf. Back in 


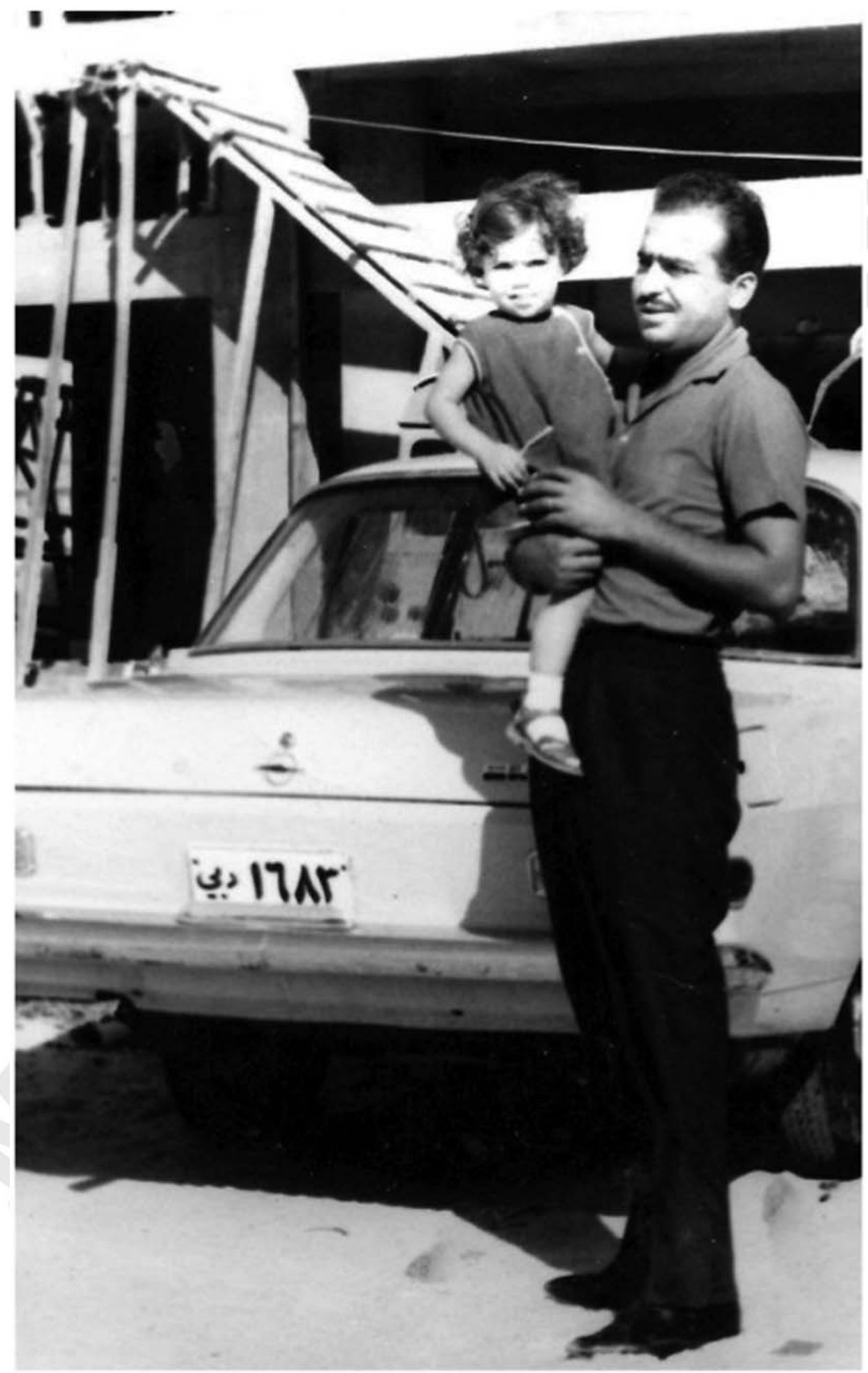




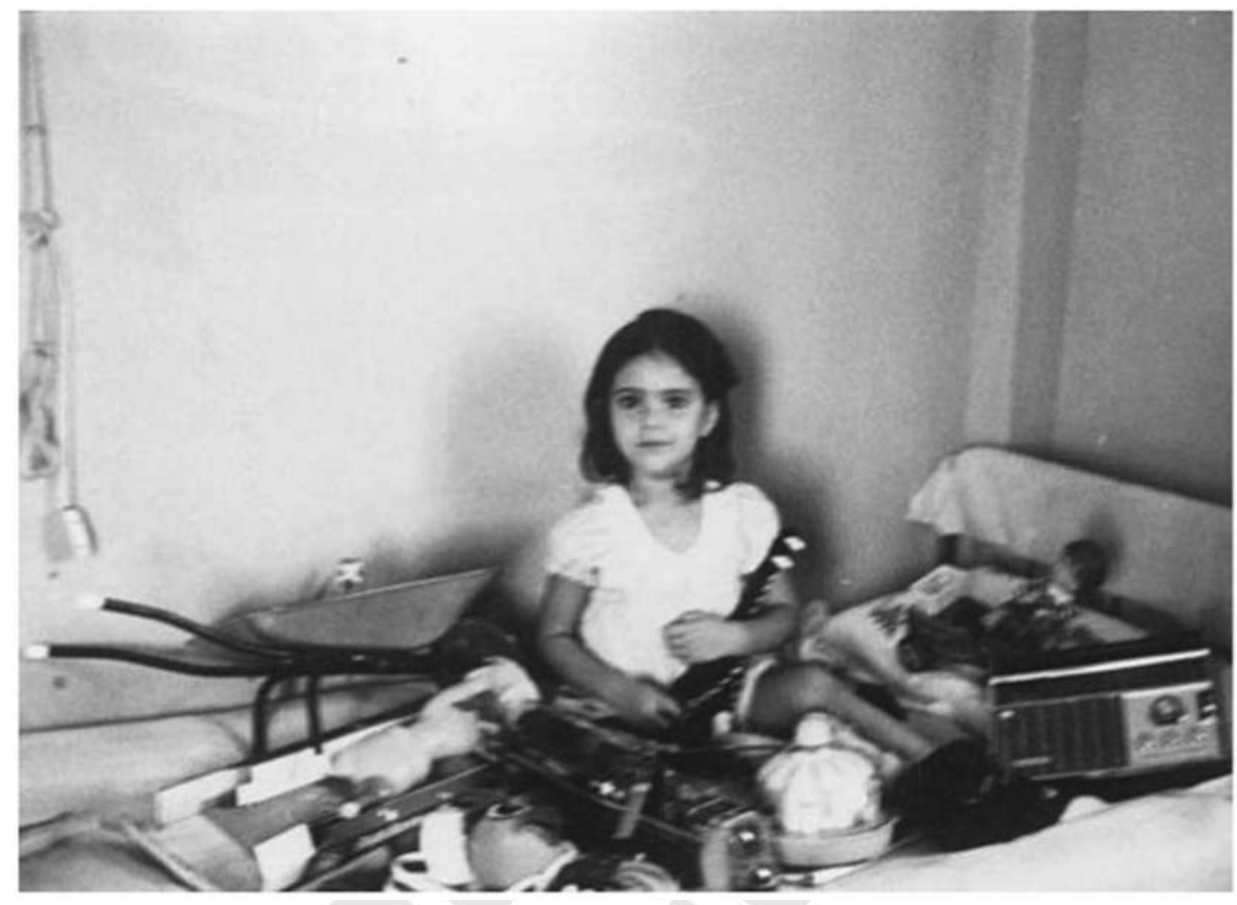

Lebanon women were educated, held jobs, and generally were making their way into the modern world albeit slowly, whereas in the Gulf it was still primarily a man's world. Female expatriates were mostly wives though some of them may have also worked as nurses, midwives, or teachers. These were certainly the main occupations open to women. Yet my mother is daring to imagine the truly unimaginable, albeit as a light-hearted scribble on the back of a fading photograph.

\section{Crossing a Third Boundary: My Toys}

This photograph shows me and my toys. I was around four years old and by then we had moved to the little oasis town of Al-Ain. Our house was a traditional local dwelling, with a large garden, in which I kept a very special pet. But more of that later.

The interesting thing about this photograph is the collection of toys I had. If we were to look closely we would see me holding a dolly, but that was probably the only 'girl' toy in the collection. The rest show far less 'female gendering'. I have a wheelbarrow, a train, a car, as well as other toys that are not clearly discernible. Other photographs show me playing a little toy piano, yet another one of my mother's aspirations for me.

But the toy that stays in my mind the most is an aeroplane, a battery-operated one with a Perspex top that allows a view of the inside of the plane. Inside at one end is a small plastic figure of the air stewardess holding up a tray. At a push of a 
button she glides all the way to the front past the seats and then all the way back. I loved that toy. It was my favourite. But it was also a representation of something I was very familiar with, as we flew home at least once a year if not more. Flying in an aeroplane was as commonplace as driving in a car for me. It was a part of my childhood.

Reflecting on the toys I had in those early years, I can only conclude that they were a product of my parents' own self-image and aspirations. My parents were young Lebanese Arabs who looked to a progressive future. They had left traditions behind and saw modernity as both a goal and a way of life. In their dress, social behaviour, and their choice to be pioneers in an emerging country, they were looking to create a future dramatically different from their parents'. They saw me (I was then the only child) as an extension of that self-image and aspiration. My toys, which they chose for me, reflect not only a familiar reality but also a confidence in their imagined future. Since we were living in a society dramatically different from the one back home in Lebanon, social conventions, including gender roles, did not apply to the same extent. My toys reflect more my father's occupation, the shovel and wheelbarrow, and my mother's frustrated aspirations, the piano. I have since asked my mother why I did not have any cooking toys and her reply was that she didn't see me as growing up to be a housewife. She saw housework as a chore of which their growing wealth would relieve her, as it eventually did. We always had daily help in the form of the 'house boy' as the domestic foreign workers (mainly Indian men) were known in the Gulf region.

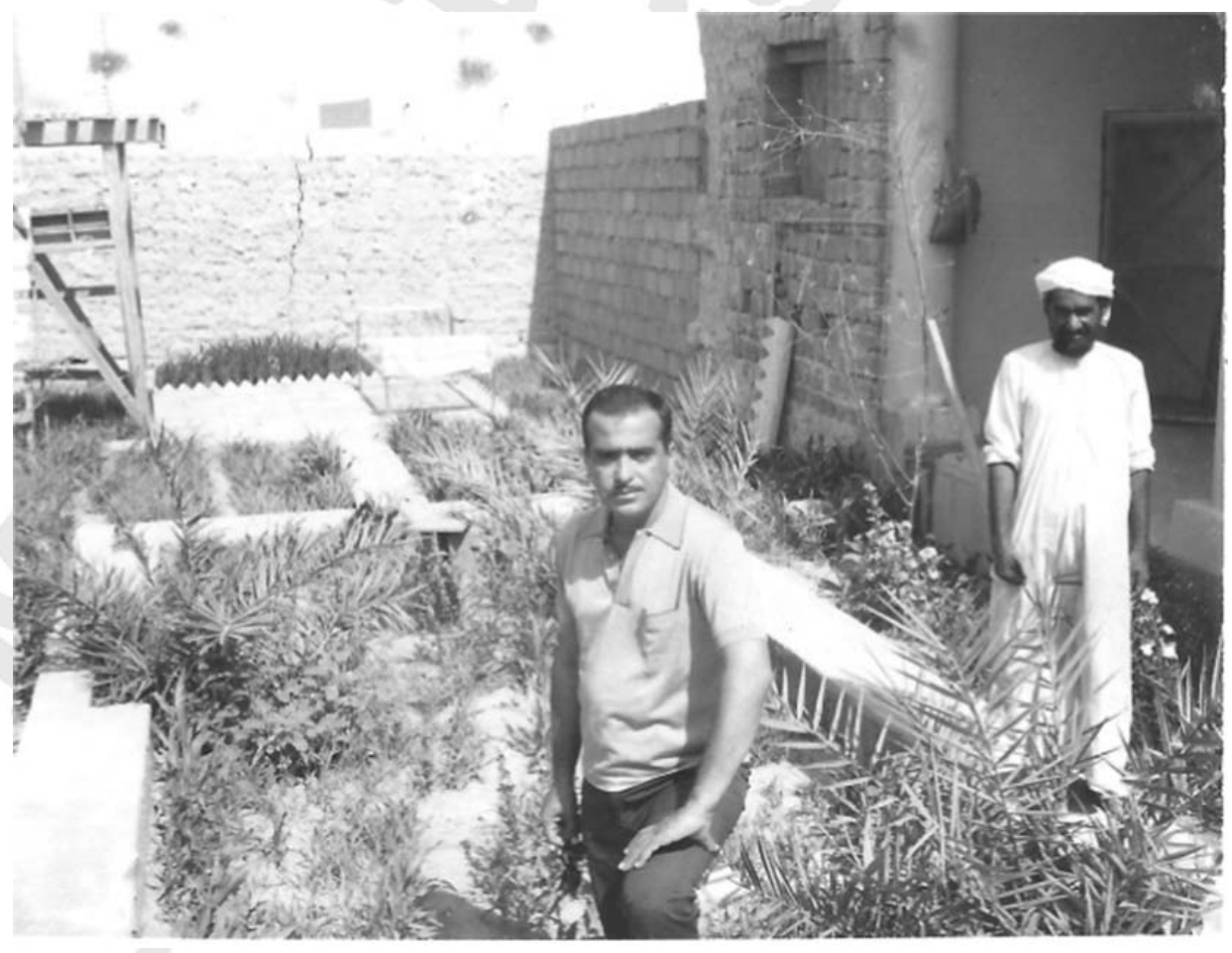


One anecdote was retold to me by my mother over the years. When I was around four years old, one of my father's bachelor friends whenever he visited us would tease me by asking me if I would marry him. I would always say no. One day he asked me 'why not?' and I replied 'Do you think me stupid? So I can be a servant?!'

It is difficult to discern the usual Western-orientated class and gender demarcation lines when reviewing my childhood and its artefacts. In fact finding a suitable theoretical framework to examine it and make sense of it is a challenge. It doesn't fit neatly into the usual discourses around post-colonial experiences or a class struggle.

The nearest explanation I have is that my parents saw me as an extension of themselves. As their child I was a manifestation of their self-identity and aspirations.

A photograph that exemplifies this for me is the one of my second birthday. I am carried by my mother as I blow the candles out on a two-tier cake. The distinctive feature of this photograph is the lack of children in it. Although it was my birthday, it was really a celebration for my parents of their parenthood with their friends witnessing it. It wasn't really done for my benefit but for theirs. I do not say that with bitterness or regret. It simply is a realisation that I have come to over the years. Perhaps it is cultural, but certainly as I grew up, for myself and my contemporaries it was rare that celebrations or special occasions were childcentred. Mostly they were about adults with us the children in the background as opposed to the foreground.

\section{Hak-Hak, My Childhood Pet}

Another particular aspect of my childhood in the UAE was my pet Hak-Hak. HakHak was a pet goat. Not that goats were generally kept as pets either in the Gulf

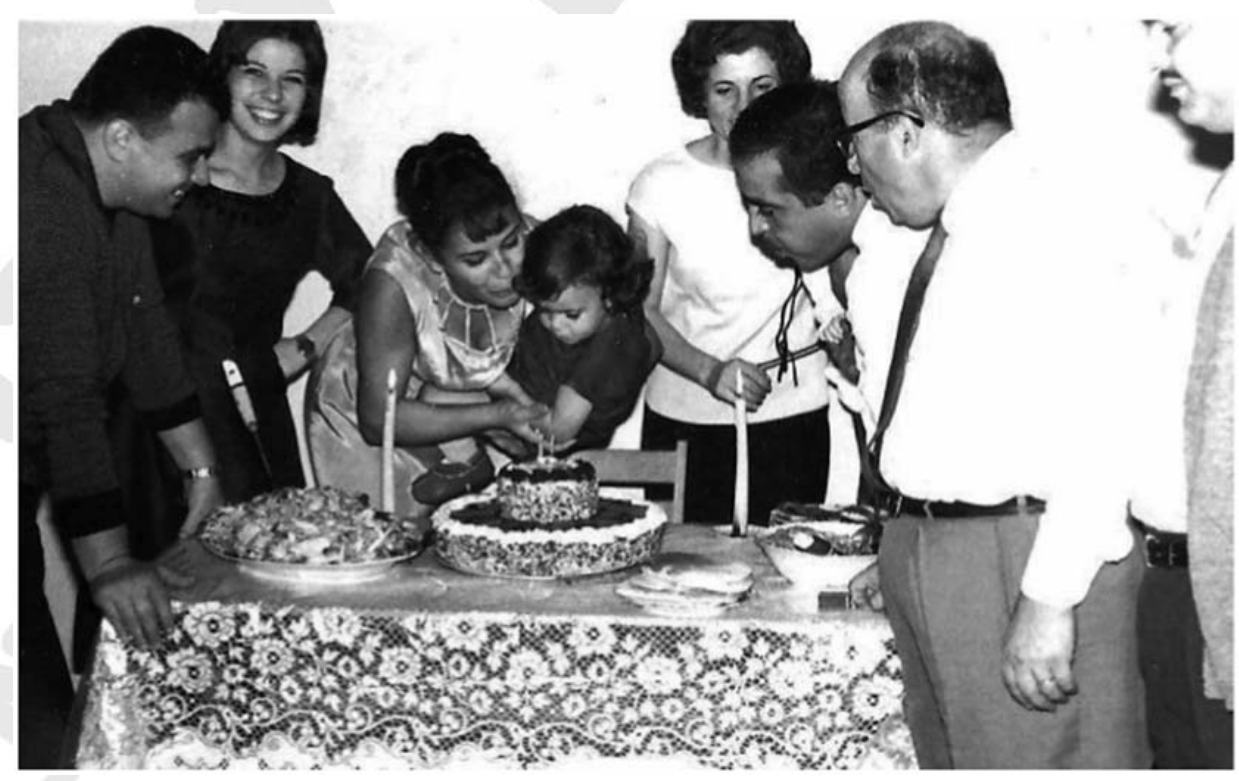




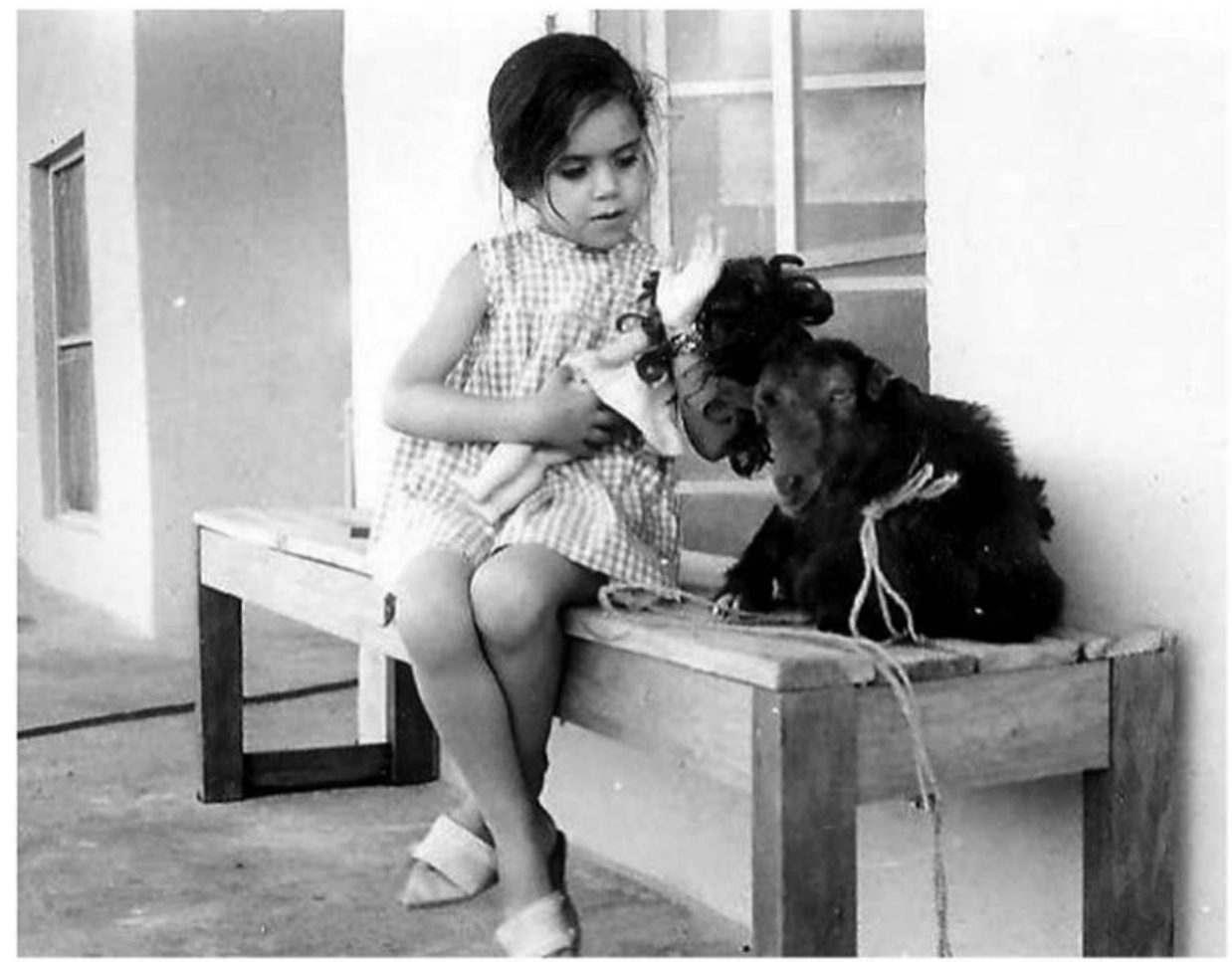

FIGURE 7 With my pet goat Hak-Hak.

region or in Lebanon. In fact I was told many years later that Hak-Hak was never meant to be a pet for me. My parents had originally procured him to slaughter and barbecue for their friends. But when he arrived at our home in Al-Ain I took to him so they decided they would let me keep him for a while.

Having a pet is not in itself a strange occurrence. But having a goat for a pet in my view demonstrates the 'maverick' progressive attitude of my parents. They were ready to try new unconventional things. And as the photo of Hak-Hak and me show, he was a happy goat!

A little while after this picture was taken, I flew back to Lebanon with my mother in order to be admitted to boarding school. My parents did very little to prepare for that drastic change. In fact their idea of preparing me for boarding school was to tell me that I ought to give my toys away to my friend Therese, since where I was going I would only be allowed one toy. I couldn't work out why I should do that and as I remember was rather resentful that they should order me to give my toys away. I remember clearly taking a hammer to my favourite toy, the airplane. When my parents found me smashing the plane to bits, they were horrified and accused me of being mean and smashing the plane so Therese couldn't have it (which strangely was true I think). My response, which I recall very clearly, was that Therese was very welcome to the plane but that the hostess inside the plane was mine and I wished to keep her, hence smashing the plane so I 


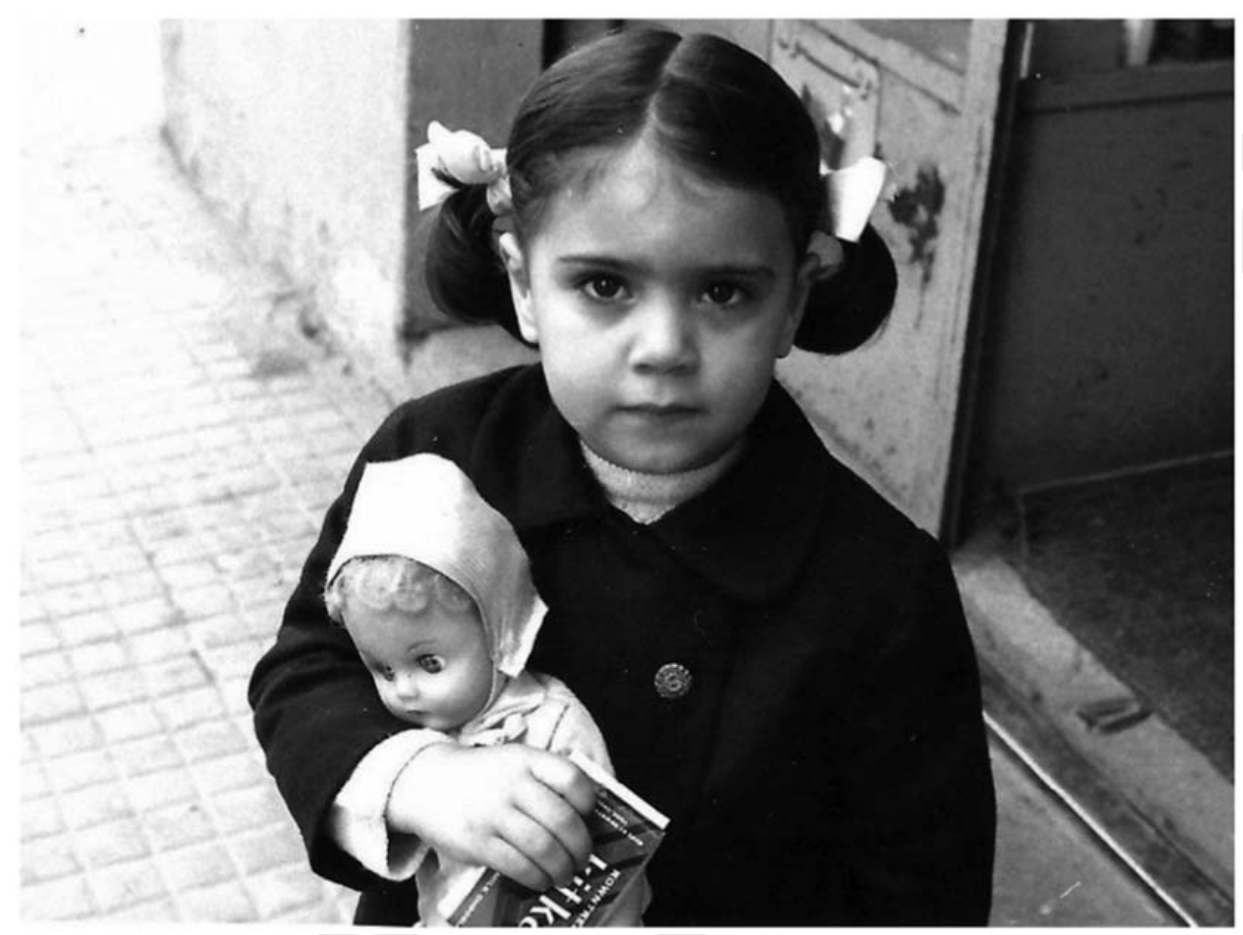

FIGURE 8 Myself, aged four, and the doll I was allowed to take.

could get her out. I don't remember if I got to keep the hostess. I was allowed to keep one doll.

\section{Crossing the Religious Boundary: Going to School}

Having spent the first four years of my life crossing between the two cultures of Lebanon and the Emirates, I was about to cross an even more significant boundary. In my first four years, at least I was accompanied by my parents in the various experiences I had in the Emirates. But as I was left in the care of the nuns that morning, I was facing a new reality all on my own. I was soon to start experiencing the differences belonging to a particular group can make when you are the odd one out. And as a Muslim girl I was the odd one out at my school. My memory is that I was one of three Muslim girls, the other two being sisters.

Different faith groups in Lebanon are ethnically the same. We are all Lebanese. We do not look different in our physical appearance. Even clothing in those days was the same between the different faith groups. The hijab as we know it now was not prevalent. My school as well was a testament to my parents' growing affluence. It was a very expensive private boarding school, albeit a convent. The sisters of the Holy Family had a good business sense.

But affluence did not provide protection from prejudice. What became quickly apparent was that I stood out from the other children. Perhaps it was growing up in the emirates, perhaps it was my surname (in Lebanon family names are an 
indication of faith and sect, mine being a Sunni Muslim surname). But from the start I started to be excluded by the other kids. Eventually that would turn to 'mild' bullying. I recall walking the playground alone as no other girl would play with me. When I picked up a cucumber that someone had dropped and wiped it to eat it, the girls started shouting at me that the devil had licked it. Many nights I simply cried myself to sleep.

There is much to recount about coming to an awareness of being the unwanted other. What the other girls and even some of the teachers made me feel was that somehow I was inferior because of my faith. One notable incident happened in my third year at school. I was seven years old. Our class teacher Demoiselle Layla whom I adored had asked us to give her the name of one of our uncles. The girls would in turn shout an uncle's name. Now I have four maternal uncles who doted on me and with whom I had spent alternate weekends for the three years I had been in boarding schools. I could have chosen my favourite uncle Fouad. He was the one who always ferried me around and spoilt me rotten. And he also had a name that was not faith-specific. Many Christians are called Fouad. To this day I have no idea why I chose the uncle whose name could only be a Muslim name, Abdullah. No sooner had I said his name than the class erupted with laughter and I promptly burst into tears. Mlle Layla looked very cross and ordered me out of the class. Sobbing I went out wondering why I was being punished for the cruelty of the others. A few minutes later Mlle Layla followed me in the corridor, she took me by the shoulders, looked me in the eyes and told me that I had nothing to be ashamed of and I should never give them the satisfaction of making me cry. It was one of the best lessons in resilience any child could have.

\section{A Brief Sketch: My Grandmother}

When I was sent to boarding school, my home for the next six years on alternate weekends and some of the school holidays was my maternal grandmother's house in Beirut. If I am recollecting memories with a particular perspective then these have definitely been formed by spending several years between the ages of four and eleven with and around my maternal grandmother and family.

My grandmother, Teta Nahla, was a formidable lady. She had been widowed relatively young, around the age of thirty-six. My grandmother hailed from the Shatila family, a well-known, land-rich Ras-Beirut* family. When she married my grandfather, her maternal cousin from the Labban family, another well-known Ras-Beirut family, she was around fifteen years old. He was around nineteen. When he died aged forty she was left with six children, the eldest disabled and the youngest one only one month old.

Like other women of her class and background, my grandmother never worked. When she married, her paternal family the Shatilas gave her land at the heart of the capital in Ras-Beirut (the equivalent of Park Lane in London) where she and my grandfather built a home.

My grandmother had a strong presence. She was confident, perhaps a confidence that comes from being secure in knowing one's social place. As a widow she managed the income from a meagre police officer's pension. Although I was only a 
child, I was aware of the fact that Teta Nahla had far less money than other wealthier relatives. She was an expert at economising and making a lot from very little. Her home was spacious and beautifully, though not expensively, furnished. She had put her children through school and further training so my uncles had good employment, but of course neither my mother nor my aunt (the two girls) were expected or encouraged to work. My purpose in giving this brief sketch of my grandmother and her home is to situate the burgeoning of my own identity and the roots of the meaning-making psychological framework that helped to create my world view and my gender identity.

Growing up in boarding school in Lebanon I was painfully aware of the absence of my mother whom I idolised. But I also had the maternal figure of my grandmother whose life and struggles shaped my more immediate reality and sense of the world. My mother was this stunning beauty living in the desert and oases of the Gulf, which although I visited regularly was only an intermittent home. I was always a temporary visitor, knowing I was only there for a few weeks before I had to get the plane back to Lebanon and boarding school. And although Ras-Beirut and my grandmother's and great aunts' homes and families provided an alternate home, my sense of belonging physically there was always curtailed first by the limited time of my stay, weekends and some holidays, and also by the fact that a part of me longed to be with my parents in another place.

But although my sense of belonging to my maternal family was never complete it still gave me strong roots on which to build an identity. It was less of an anchor and more of a pole to which I could choose to tether my identity lest it drifted and got lost. At different times of my life, that tether has proved very salutary.

\section{On Being Forever a 'Foreigner'}

Not speaking one's mother tongue. Living with resonances and reasoning that are cut off from the body's nocturnal memory, from the bittersweet slumber of childhood. Bearing within oneself like a secret vault ... that language of the past that withers without leaving you. (Kristeva, I99I: I 5 )

One might also add to one's memories, the mother tongue. Memories of another self, another state of being, hidden deep in the vault of the past along with the old language. And here this old language, the mother tongue, is not just a collection of vocabulary and grammar, but far more. It is the daily intonations of a linguistic form; the particularities and peculiarities of a language that was of its time and place and can no longer be. Not because the place is gone or the person is gone from the place, but because the present is vastly foreign to the past. Beirut and Lebanon now, as well as Dubai, Al-Ain, and Abu Dhabi are not the places I knew as a child. Only in the memory and the scribbles on fading photographs is the old language preserved.

So what of my identity at present? The themes that have emerged in this paper have posed more questions in my mind as to the extent that my identity has been forged through the reaction to always being a foreigner. I have found particular resonance with Kristeva's analysis of not belonging and how that impacts on the 
way we see ourselves and others. But more importantly for me, I am left wanting to explore further the trajectory of the women in my family and the extent to which their experiences, expectations and aspirations forged my own trajectory.

There are some who might argue that modernity in itself alienates us and that in the mass world of universal institutions our identity is proscribed and controlled; others dispute this reductionist view and argue that there is a complexity and universality to becoming modern, and it is in the interface between structure and agency on many different levels that we can understand it (Giddens, I99I). The social, economic, and technological factors that led to our modernity meant that the life paths of three generations of women - my grandmother, my mother, and myself - have been vastly different though strangely continuous. Looking back at my childhood, I find myself only able to make sense of it through situating it in the adult world that shaped it. But having done that, it has allowed me to start to make sense of the present.

\section{References}

Barakat, H. I993. The Arab World: Society, Culture, and State. Berkeley, CA: University of California Press.

Bignold, W. 20I I. Creative non-fiction: one approach to narrative research in education. Educational Futures 4(I), I9-27.

Gettleman, M. and Schaar, S. (eds.). 2003. The Middle East and Islamic World Reader. New York: Grove Press.

Giddens, A. I99I. Modernity and Self-Identity. Polity Press: Cambridge.

Hepburn, A. 2003. Critical Social Psychology. London: SAGE.

Jenkins, C. 2005. Childhood. Oxford: Routledge.

Kristeva, J. I99I. Strangers to Ourselves. New York: Columbia University Press.

Makdisi, U. I996. Reconstructing the Nation-State: The Modernity of Sectarianism in Lebanon. Middle East Report, No. 200, Minorities in the Middle East: Power and the Politics of Difference (Jul.-Sep., I996), pp. 23-26, 30, Middle East Research and Information Project.

Pollock, D. and Van Reken, R. 2009. Third Culture Kids. London: Nicholas Brealey Publishing.

Schaffer, H. 1996. Social Development. Oxford: Blackwell Publishing.

Thesiger, W. 1959. Arabian Sands. London: Longmans.

Turmel, A. 2008. A Historical Sociology of Childhood. Cambridge: Cambridge University Press.

Watenpaugh, K. 2006. Being Modern in the Middle East: Revolution, Nationalism, Colonialism and the Arab Middle Class. Princeton, NJ: Princeton University Press.

Wetherell, M. (ed.). I996. Identities, Groups and Social Issues. Milton Keynes: The Open University.

'The Story of the UAE', Available at: < http://www.zu.ac.ae/main/en/_careers/living/story.aspx > [Accessed I 2 June 2014 .

\section{Notes on contributor}

Rania Hafez, Department of Education and Community Studies, Faculty of Education and Health, University of Greenwich, Avery Hill Campus, Mansion Site, Bexley Road, London SE9 2PQ, UK. Email: r.hafez@gre.ac.uk 